\title{
Valor diagnóstico del estudio médula ósea en pacientes VIH
}

\section{Diagnostic value of bone marrow study in HIV patients}

Ver artículo: página 93

Dr. Carlos Alberto Betancur: Internista. Profesor Titular Universidad CES. Medellín (Colombia).

Correspondencia. Dr. Carlos Alberto Betancur J. Medellín (Colombia).

E-mail:cbetancurmed@gmail.com
Corzo y cols. en su investigación "Prevalencia de infecciones oportunistas en pacientes VIH - SIDA con base en el estudio de médula ósea", publicado en este número de AMC encuentran en 83 pacientes, 22 infecciones oportunistas $(23.9 \%)$, diagnosticadas por examen directo en $23 \%$ y por cultivo en $34.5 \%$; siendo infecciones micóticas el $23.8 \%$ aislando como germen predominante el Histoplasma capsulatum. De los 22 pacientes infectados con sólo el estudio microscópico se diagnosticó en 17 (1). Comparativamente, en Brasil se ha obtenido un rendimiento diagnóstico en el estudio de médula ósea de $34.1 \%$ en pacientes con VIH y citopenias (2); en Texas, de 57 muestras resultaron positivas para infecciones oportunistas 24, predominando las micobacterias (3) y en India, de 30 pacientes $27.6 \%$ fueron diagnosticados por este método (4).

La infección micótica que más compromete la médula ósea es la producida por histoplasma seguida de criptococo. En histoplasmosis diseminada en paciente VIH la médula se ve comprometida en $80 \%$ de los casos, viéndose en coloraciones como PAS Plata metenamina, Wrigth (5).

Las micosis invasivas en pacientes inmunosuprimidos requieren diagnósticos rápidos; el estudio de tejido comprometido y el de la médula ósea nos ayudan al diagnóstico cuando no se ha aclarado la etiología por otros métodos. La microscopia nos muestra si hay levaduras, el tamaño su forma de gemación (histoplasma) y la presencia de cápsula (criptococo) y las hifas si son septadas (aspergillus) o no septadas (mucorales) si se ramifican en 45 grados el primero o en 90 los segundos. Coloraciones como el Gram, ZN, Plata metenamina, PAS, Alcian Blue son indispensables, y el riesgo de contaminación de la muestra es mínimo. La coloración de plata metenamina es más sensible que el PAS, pero esta última muestra mejor la reacción tisular al hongo. Se pueden complementar con técnicas de hibridización in situ como el PNA-FISH que puede identificar especies de Candida y su resistencia al fluconazole (6, 7). La tinta china es de gran especificidad en líquido cefalorraquídeo para Criptococcus, y contamos con técnicas de flujo lateral comerciales para la detección del antígeno capsular CRAG tanto en LCR como en suero (8-10).

En infecciones por $P$ jirovecci, la técnica de inmunofluorescencia con calcoflour es confiable en LBA para el diagnóstico en el paciente sin sida, pero en el paciente VIH es suficiente la muestra de esputo inducido con buena sensibilidad; la inmunoflorescencia directa tiene sensibilidad $86-97 \%$ pero estudios recientes muestran más sensibilidad de la PCR en muestras profundas (10). En Medellín Vélez y colaboradores encontraron mejores resultados con inmunofluorescencia directa que con azul de toluidina en lavado broncoalveolar. (11). En histoplasmosis a más del examen directo y en estudios tisulares, las pruebas serológicas de anticuerpos son de bajo valor en infecciones agudas, pero contamos en nuestro medio con la detección de antígeno medido por ensayo inmunoanálisis en suero y en orina con sensibilidad de $86 \%$ y especificidad de $94 \%$ en estudio de 28 pacientes con sida e histoplasmosis (12)

El antígeno aspergilar, galactomannan es más sensible que el cultivo, es de amplio uso en monitoreo y diagnóstico de pacientes con leucemia con sensibilidad muy variable (17-100\%), pues tiene falsos negativos en pacientes recibiendo profilaxis o tratamiento antimicótico y falsos positivos dependientes de dieta y medicamentos, su valor predictivo positivo es dependiente de la prevalencia de la enfermedad y se debe hacer seriado (10). En Bogotá los resultados fueron pobres, de 13 pacientes con aspergilosis, sólo cinco resultaron positivos (13). El 1.3 beta D Glucano es un carbohidrato de la pared celular del hongo, se produce en infecciones por Aspergillus, Candida Pneumocystis, pero no en Crypotococcus spp y mucorales, tiene alto valor predictivo negativo en infección invasiva (10).

La detección de antígeno y anticuerpo para Candida (mannan y antimannan), no ha tenido 
buenos resultados, igual sucede con PCR para candida y aspergillus y con el panfungalassay con poca evidencia al momento (10). Recientemente la Asociación Panamericana de Infectología (API) publicó el Manual de Infecciones fúngicas sistémicas, donde establece las reglas para el adecuado diagnóstico por cultivo en casos de candidemia, y el manejo de las micosis en general (14).

Corzo y colaboradores en su investigación (1) encuentran Tb en médula ósea, en tres pacientes que equivale al $10.8 \%$ de los estudiados, todos ellos por examen microscópico, no tienen estudios de PCR complementarios que pudiera aumentar la eficiencia diagnóstica.

La linfopenia y trombocitopenia en pacientes con Tb sugieren afección de la médula ósea siendo principalmente por $\mathrm{M}$ tuberculosis $\mathrm{y}$ avium-intracelulare (15). El pilar diagnóstico de la tuberculosis es la observación del bacilo en el ZN o su aislamiento en los cultivos. Las formas paucibacilares y la $\mathrm{Tb}$ extrapulmonar presentan a menudo dificultades diagnósticas. La baciloscopia resulta positiva en las formas diseminadas o cavitarias hasta en el $90 \%$ de los casos; en paciente con solo infiltrados pulmonares esta positividad desciende al 50-80\% y en las ganglionares a un $50 \%$. Contamos para estos casos con herramientas diagnosticas utilizables en el esputo, en líquidos y en tejidos con resultados rápidos y confiables. El Gen XpertMTB/RIF es una prueba automatizada utilizando la PCR en tiempo real que amplía el genoma rpoB (responsable de casi todas las formas de resistencia de la micobacteria a la rifampicina) lográndose con ella no sólo comprobar el diagnóstico, sino si hay resistencia a la rifampicina. Su resultado se obtiene en pocas horas siendo positivo en $98.2 \%$ de las muestras positivas en el directo $y$ en $72.5 \%$ de las muestras que siendo negativas en el directo, son positivas en el cultivo (16). Otras pruebas menos difundidas por técnicas de hibridización en fase sólida, son las que a más de la detección del bacilo censan la resistencia además de la rifampicina (rpoB) a la isoniazida (kat G) (Genotype MTBDR plus) y a quinolonas y amicacina, kanamicina y cicloserina y etambutol (Genotype MTBDRsl), pero hay dudas por presentarse casos de falsos negativos (17).

La OMS está desarrollando una prueba tanto antigénica como de detección de anticuerpos en orina para uso más generalizado en casos de sospecha de tuberculosis con baciloscopia negativa que es la LAM: lipoarabinomanan $(18,19)$.

Es importante agotar todos los métodos diagnósticos en el estudio de nuestros pacientes inmunosuprimidos con infecciones oportunistas para con ello agilizar su manejo y mejorar el pronóstico.

\section{Referencias}

1. Corzo RJ, Rojas ME, Figueroa CL, Daza N. Prevalencia de infecciones oportunistas en pacientes VHI-SIDA con base en el estudio microscópico de médula ósea. Acta Med Colomb 2015;40: 93-100.

2. Tanaka PY, Hadad DJ, Barletti SC, Aparecida S, Calore EE. Bone marrow biopsy in the diagnosis of infectious and non-infectious causes in patients with advanced HIV infection. Journal of Infection 2007: 54:362-6.

3. Quesada AE, Tholpady A, Wanger A, Nguyen AN, Chen L. Utility of bone marrow examination for workup of fever of unknow origin in patients with HIV/AIDS. J Clin Pathol 2015;68:241-5.

4. Pande A, Bhattacharyya M, Pain S, Ghosh A, Samanta A. Diagnostic yield of bone marrow examinagtion in HIV assocaited FUO in ART naive patients. J Infect Public Health 2010;3:124-9

5. Assi MA, Sandid MS, Baddour LM, Roberts GD, Walker RC. Systemic histoplasmosis: a 15 year retrospective institutional review of 111 patients. Medicine (Baltimore)2007;86:162-9.

6. Stone NR, Gorton RL, Barker K, Ramnarain P, Kibbler CC. Evaluation of PNA-FISH yeast traffic light for rapid identification of yeast directly from positive blood cultures and assessment of clinical impact. J Clin Microbiol 2013; 51: 1301-02.

7. Farina C, Perin S,Andreoni S, Conte M, Fazil P, Lombardi $\mathbf{G}$, et al. Evaluation of the peptide nucleic acid fluorescence in situ hybridisation technology for yeast identification directly from positive blood cultures: an Italian experience. Mycoses 2012; 55: 388-92.

8. Babady NE, Bestrom JE, Jespersen DJ, Jones MF, Beito EM Binniker MJ, Wengenack. Evaluation of three commercial latex agglutination kits and a commercial enzyme immunoassay for the detection of cryptococcal antigen. Med Mycol 2009; 47: 336-38.

9. Jarvis JN, Percival A, Bauman S, Pelfrey J, Meinties G, Wiliams GN, et al. Evaluation of a novel point-of-care cryptococcal antigen test on serum, plasma, and urine from patients with HIV-associated cryptococcal meningitis. Clin Infect Dis 2011; 53: 1019-23.

10. Schelenz S, Barnes RA, Barton RC, Cleverley JR, Lucas SB, Kibbler CC, et al. British Society for Medical Mycology best practice recommendations for the diagnosis of serious fungal diseases. Lancet Infect Dis 2015 Published Online March 12, 2015

11. Rodiño J, Rincon N, Aguliar A, Rueda Z, Herrera M, Velez LA. Diagnóstico microscópico de neumonía por $P$ jiroveciide lavado broncoalveolar y lavado orofaríngeo de pacientes inmunocomprometidos con neumonía. Biomédica 2011;31:222-31.

12. Caceres DH, Scheel CM, Tobon A, Ahiquisi A. Restrepo A, Brandt ME, et al. Validation of an enzyme-linked inmunosorbent assay that detects Hitoplasma capsulatum antigenuria in Colombian patients with AIDS for diagnosis an follow-up during therapy. Clin Vaccine Inmunol 2014;21:1364-68.

13. Saenza V, Arizab BE, Alvarez C. Utilidad clínica de la detección antigénica de galactomanano en el diagnóstico de aspergilosis invasora en un hospital universitario de tercer nivel en Bogotá 2010-2012 Infectio 2012;16:31-37.

14.Celi AP, Riera F, Thompson L. Manual de infecciones 
fúngicas sistémicas. Asociación Panamericana de Infectología Mayo 2015.

15. Lombard EH, Mansvelt EP. Haematological changes associated with miliary tuberculosis of the bone marrow. Tuber Lung Dis 1993; 74:131-5.

16. Boheme C, Nabeta P, Hilleman D, Nicol MP, Shenai S, Krapp F, et al. Rapid molecular detection of tuberculosis an rifampin resistence. NEJM 2010;363:1005-15.

17. Theron G, Peter J, Richardson J, Barnard M, Donegan S, Warren R, et al. The diagnostic accuracy of the GenoType
MTBDRs lassay for the detection of resitence to second-line antituberculosis drugs. Chocrane Databsesyst Rev 2014;10:4-123.

18. Drobniewsky F, Nicolayevsky V, Balabanova Y, Bang D, Papaventsis D. Diagnosis of tuberculosis and drug resistence. What can new tool loss bring us? Int J Tuberc Lung Dis. 2012;16:860-70.

19. Ortega H. Actualización en métodos diagnósticos para tuberculosis. En: XV curso de residentes de Medicina Interna. 2015. Editores Giraldo S, Miranda F, Vallejo L. Editorial Artes y Letras SAS. 465-479 